\title{
Representasi peran ibu dalam film Ibu Maafkan Aku
}

\author{
Dila Febriyanti', Muhamad Ramdhani², Flori Mardiani Lubis ${ }^{3}$
}

${ }^{1,2,3}$ Universitas Singaperbangsa Karawang, Karawang, Indonesia

\begin{abstract}
ABSTRAK
Film Ibu Maafkan Aku merupakan film drama karya Amin Ishaq. Film yang menceritakan bagaimana peran ibu dalam keluarga, mendidik anak dan dengan banyak nya perjuangan serta pengorbanan dan sebagainya. Peran ibu dalam film ini diperankan oleh Christine Hakim. Dalam film ini peran ibu menjadi peran ganda, karena bapak yang sudah meninggal dunia. Meski harus menghidupi keluarga nya sendiri, peran ibu dalam film ini sangat berperan penting karena peran ibu dalam film ini yang akan di teliti lebih spesifik dan film ini menjadi simbol bahwa peneliti sangat menghargai atas segala perjuangan dan pengorbanan yang telah ibu berikan. Oleh karena itu peneliti tertarik untuk menganalisis film Ibu Maafkan Aku sehingga penelitian ini berjudul Representasi Peran Ibu Dalam Film Ibu Maafkan Aku. Fokus penelitian ini adalah level realitas, level representasi, dan level ideologi. Penelitian ini menggunakan metode kualitatif penelitian yang bermaksud untuk memahami fenomena tentang apa yang di alami oleh subjek penelitian, penelitian ini menghasilkan data deskriptif berupa kata-kata tertulis atau dari lisan orang-orang, perilaku. Dan dengan analisis semiotika untuk mengkaji tanda, teks, dan simbol. Dalam metode ini akan di jelaskan bagaimana adanya makna, tanda, dan simbol. Penelitian ini menggunakan analisis semiotika Jhon Fiske berdasarkan kode-kode televisi yang terbagi menjadi tiga level realitas, representasi dan ideologi. Teknik pengumpulan data pada penelitian ini adalah soft file film dan studi pustaka. Hasil yang diperoleh dari penelitian ini adalah adanya ideologi ibu isme pada film Ibu Maafkan Aku yang direpresentasikan melalui beberapa scene film yang di antaranya mengenai penampilan/ cara berpakaian, gestur, ekspresi, perilaku, riasan wajah, lingkungan, teknik pengambilan gambar, kamera, pencahayaan, karakter/penokohan dialog, musik.
\end{abstract}

Kata-kata Kunci: Peran ibu; semiotika; level realitas; level representasi; level ideologi

\section{Representation the Mother's Role in the Film "Ibu Maafkan Aku"}

\begin{abstract}
The film "Ibu Maafkan Aku" is a movie drama by Amin Ishaq. The film tells the mother's role in the family, educating children with many struggles and sacrifices and so on. The role of the mother in this film is played by Christine Hakim. In this film, the mother's role is doubled because the father has passed away. Although she has to support her own family, the mother in this film plays an important role, this is what will be examined more specifically. This film is a symbol that researchers really appreciate all the struggles and sacrifices that mothers have given. Researchers are interested in analyzing the film "Ibu Maafkan Aku", focusing on the level of reality, the level of representation, and the level of ideology. This study uses qualitative methods to understand phenomena about what is experienced by the research subjects that produce descriptive data in the form of written or oral words and people's behavior. This study uses John Fiske's semiotic analysis to examine the existence of meanings, signs, texts and symbols based on television codes that are divided into three levels of reality, representation and ideology. Data collection techniques in this research are soft file films and literature study. The results obtained from this study are the ideology of mother-ism in the film "Ibu Maafkan Aku" represented by several film scenes including the appearance or dressing style, gestures, expressions, behavior, facial makeup, environment, shooting techniques, cameras, lighting, characterization, dialogue and music.
\end{abstract}

Keywords: Role of mothers; semiotics; reality level; level of representation; ideology level

Korespondensi: Dila Febriyanti, S.I.Kom. Universitas Singaperbangsa Karawang. Jl. H.S. Ronggowaluyo Teluk Jambe Karawang41361.Email:Dila14febriyanti@gmail.com 


\section{PENDAHULUAN}

Film merupakan media massa, ada pesan di dalam sebuah film ketika ditonton kemudian dimaknai oleh khalayak atau yang menonton. Adanya beberapa kalangan memandang sebuah film sebagai hasil karya seni serta sebagai ruang ekspresi yang bebas dalam sebuah proses pembelajaran untuk lebih mengembangkan diri pada bidang perfilman dan adanya kelompok lainnya cenderung memaknai film sebagai realitas empiris yang merekam secara jujur nilai-nilai sosial yang terjadi dalam suatu masyarakat (Vera, 2014).

Film adalah media yang menyampaikan topik atau pesan secara ringan sehingga mudah dipahami oleh penonton. Film merupakan media yang memiliki daya jangkau sangat luas, bahkan film bisa diakses hampir seluruh dunia dan pada waktu yang bersamaan (Sutorini et al., 2019).

Dalam perkembangannya, sebagai suatu ilmu komunikasi telah melahirkan apa yang disebut dengan komunikasi massa yang tentu saja membutuhkan bantuan media massa dalam proses penyampaian pesan dari komunikator kepada komunikan. Media massa modern yang kita ketahui saat ini terbagi ke dalam lima jenis, yaitu: Surat kabar/Pers; Radio; Televisi; Film; dan Internet (Abidin et al., 2017).

Komunikasi massa adalah komunikasi yang di sampaikan kepada khalayak dengan menggunakan media sebagai perantaranya untuk menyampaikan pesan. Salah satu untuk menyampaikan ide/gagasan salah satu nya melalui film (Permana et al., 2019). Film adalah sebuah media dari komunikasi massa yang bersifat audio visual untuk menyampaikan pesan pada yang menonton supaya mendapat pertukaran pesan. Komunikasi massa mampu menyebarkan pesan kepada khalayak luas secara bersamaan dalam satu kali penyampaiannya (Budiman \& Ajidarma, 2004). Sosialisasi mengarahkan individu agar mendapatkan perilaku yang baik dalam sebuah kelompok. Serta media massa memberikan dan menunjukkan dengan apa yang akan diharapkan. Dengan kata lain dari suatu peran atau model dapat di tirukan oleh khalayaknya yang memahami (Ardianto et al., 2007).

Secara khusus adanya sarana untuk mengirimkan atau meneruskan budaya, media massa juga berkontribusi untuk meneruskan nilai-nilai historis yang ada dalam masyarakat. Media massa dapat meng nilirimkan atau meneruskan adanya nilai-nilai budaya melalui sejarah yang ada. Generasi sebelumnya banyak menyapaikan pesan lewat beberapa media seperti buku dan berbeda-beda pula penyampaiannya serta media massa juga menyebarkan nilai-nilai dan ide-ide yang ada di zamannya masing - masing (Vivian, 2015). 
Seiring berjalannya waktu dalam perfilman dikenal istilah film drama merupakan genre yang secara umum bisa menjangkau cerita yang saat luas untuk mengembangkan ceritaceritanya. Dari kebanyakan adanya film-film drama bisanya di latar kan adanya setting dan menceritakan kehidupan yang sangat nyata. Konflik yang ada dalam film drama dibentuk dari lingkungan sendiri maupun dari sekitar serta di kemas dengan penuh dramatik dan haru.

Di dalam film drama yang filmnya bercerita tentang peran ibu pasti sedikit banyak akan menjadi suatu sistem sosial karena saat ini fenomena perempuan bekerja dan mengurus anak seorang diri saja ditengah kebutuhan yang melonjak bukan hal aneh di kalangan masyarakat. Peran ibu itu tidak kalah pentingnya dengan ayah, jika ayah telah tiada ibu lah yang menopang segala kebutuhan anak-anaknya dan bertambahlah tanggung jawab seorang ibu.

Seorang ibu pasti mempunyai alasan dalam bekerja selain menjalankan peran gandanya, karena merasa bosan jika berada dirumah terus-menerus. Dalam film Ibu Maafkan Aku penulis menemukan sebuah ideologi ibuisme yang mempunyai pengertian yaitu perempuan harus bisa memberikan pelayanan atau melayani suami, anak-anak, sampai masyarakat dan negara dalam pengiburumahtanggaan perempuan diharuskan memberikan tenaga kerja secara cuma-cuma tanpa mengharapkan imbalan, atau kekuasaan apapun.

Filmdrama “IbuMaafkanAku”mengandung banyak makna, di antaranya ada nasihat seorang ibu, perjuangannya membesarkan anak-anak, menarik dan inspiratif. Film "Ibu Maafkan Aku” adalah film di rilis pada 10 November 2016 dan di sutradarai oleh Amin Ishaq. Film "Ibu Maafkan Aku" pernah mendapatkan piala citra untuk pemeran terbaik yang dianugrahkan pada Christine Hakim (Batara, 2016); (Ibu Maafkan Aku (2016), 2016).

Dengan simbol tandalah manusia dapat berpikir, dengan tidak adanya tanda maka manusia tidak dapat berkomunikasi dengan baik. Semiotika dan komunikasi merupakan satu kesatuan yang sangat penting dalam perkembangan dinamika metodologi ilmiah secara konsisten dalam kajian komunikasi. Dalam semiotik model John Fiske dikenal ada tiga level, yaitu analisis pada level realitas, analisis pada level representasi, analisis pada level ideologi. (Vera, 2014).

Seorang ibu adalah orang yang rela mempertaruhkan nyawa demi lahirnya sang buah hati. Ibu sosok yang akan tetap sabar meskipun anak nya melakukan kenakalan yang tidak hanya sekali atau dua kali bahkan berulang-ulang, sang ibu akan terus siap menghadapi sanganak dan memberikan nasihat. Cinta ibu juga yang membuat sang anak mampu menghadapi masa remaja yang penuh dengan 
emosi, gejolak muda yang agak sulit terkendali, tetapi sang ibu dapat mudah melalui nya dengan penuh kasih sayang dan perhatian (Abbas, 2009).

Adanya peran ibu dalam keluarga yaitu memenuhi kebutuhan fisiologis dan psikis. Peran ibu dalam merawat dan mengurus keluarga dengan sabar, mesra dan konsisten. Ibu mempertahankan hubungan-hubungan dalam keluarga. Ibu menciptakan suasana yang mendukung kelancaran perkembangan anak. Seseorang ibu yang sabar menanamkan sikapsikap, kebiasaan pada anak, tidak panik dalam menghadapi gejolak di dalam maupun luar dari anak, akan memberi rasa tenang dan rasa tertampungnya unsur-unsur keluarga. Peran ibu sebagai pendidikan yang mampu mengantar dan mengendalikan anak, ibu juga berperan dalam pendidikan anak dan mengembangkan kepribadiannya. (Gunarsa, 2001).

Menurut Gunarsa, sebagai seorang wanita yang berperan sebagai kepala keluarga yang memiliki tanggung jawab terhadap keluarga dan memiliki tanggung jawab terhadap keluarga dengan bekerja dan mengurus segala urusan, hal ini menunjukkan pentingnya peran ibu di dalam keluarga dengan tidak hadirnya ayah. (Lirsa, 2008).

Dalam film "Ibu Maafkan Aku”, banyak menampilkan adegan-adegan peran ibu yang sangat syarat akan makna. Seperti yang dikisahkan dalam film, ibu yang membesarkan ketiga anaknya sendirian setelah suaminya meninggal. Ibu merupakan sosok yang kuat, hebat dan sabar atas segala beban yang ibu rasakan, tetapi tidak pernah ada keluhan sedikit pun untuk menjadikan anak-anaknya menjadi sukses.

Menonton film Ibu Maafkan Aku mengingatkan pada sosok ibu yang senantiasa selalu memberikan apapun untuk anaknya. Selain itu dalam film Ibu Maafkan Aku, totalitas Christine Hakim sebagai ibu sungguh powerful dan supaya emosinya tersampaikan dengan baik. Film Ibu Maafkan Aku adalah sebuah gambaran yang terjadi pada film merupakan cerita yang lumrah pada masyarakat, konflik dibungkus dengan apik dan menginspirasi agar anak bisa lebih menyayangi orang tuanya. Dengan adanya penelitian mengenai film Ibu Maafkan $A k u$ sedikit banyak pesan akan tersampaikan kepada pembaca. Latar belakang di atas yang membuat penulis ingin meneliti film tersebut dengan judul “ Representasi Peran Ibu Dalam Film Ibu Maafkan Aku”.

\section{METODE PENELITIAN}

Penelitian yang sedang di teliti berikut ini adalah penelitian kualitatif. Penelitian kualitatif menurut Moleong adalah penelitian yang bermaksud pada pemahaman dari segala sesuatu yang terjadi pada subjek penelitian. 
Yang dihasilkan pad penelitian ini adanya deskriptif serta berupa kata lisan atau tulisan dari yang di amati. Yaitu dengan kata lain bahwa penelitian kualitatif dalam konteks semiotika tidak menggunakan skema statistik (Moleong, 2011).

Pendekatan analisis semiotika John Fiske sebagai upaya untuk mengembangkan pemahaman untuk mengemukakan teori tentang kode-kode televisi. Dalam semiotika (ilmu tentang tanda) terdapat dua perhatian utama, yakni hubungan tanda tentang maknanya, dan sebagai suatu tanda dikombinasikan menjadi suatu kode (Fiske, 2014).

Teknik pengumpulan data merupakan langkah yang paling strategis dalam penelitiaan, karena tujuan utama dari penelitian adalah mendapatkan data (Sugiyono, 2012). Peneliti mengumpulkan data dengan beberapa teknik. Teknik ini digunakan sebagai prosedur penelitian yang menghasilkan data. Teknikteknik yang dapat digunakan antara lain yaitu: studi pustaka, membaca literatur sebagai bahan acuan penulis dalam menyelesaikan penelitian. Literatur tersebut dijadikan refrensi bagi peneliti. Dalam kegiatan dokumentasi, peneliti memasukkan beberapa tanda atau adegan film Ibu Maafkan Aku, dan menonton film tersebut berulang kali.

Pada semiotika Jhon Fiske adanya proses dari representasi realitas yang ada dengan objek media merupakan realitas yang di endcode media. Lalu realitas tersebut digambarkan dalam media sesuai dengan teknis genrenya setelah itu semua kode diorgansirkan dalam ideologi (Rusadi, 2015).

Fokus utama semiotik adalah teks. Model proses linier memberi perhatian kepada teks tidak lebih seperti tahapan-tahapan yang lain di dalam proses komunikasi: memang beberapa di antara model-model tersebut melewatinya begitu saja, hampir tanpa komentar apa pun. Fiske menyebutkan memiliki tiga wilayah kajian alternatif yaitu tanda itu sendiri, kodekode Televisi atau sistem di mana tanda-tanda, budaya tempat dimana kode-kode dan tandatanda dioperasi (Fiske, 2014).

Dalam kode-kode televisi yang diungkapkan dalam teori Jhon Fiske, bahwa peristiwa yang ditayangkan dalam dunia televisi telah diendkode oleh kode-kode televisi terbagi dalam tiga level, yaitu: Level realitas, peristiwa yang ditandakan sebagai realitas-tampilan, pakaian, lingkungan, perilaku, percakapan, gestur, ekspresi, suara dan sebagainya. Level representasi, realitas yang terenkode dalam encoded electronically harus ditampakkan pada technical code, seperti kamera, pencahayaan, penyutingan, musik, dialog, settting, action dan sebagainya. Level ideologi, semua elemen diorganisasikan dan di kategorikan dalam kode-kode ideologis. Menurut Fiske, ketika 
kita melakukan representasi atas suatu realita tidak dapat terhindarkan adanya kemungkinan memasukkan ideologi dalam konstruksi realitas. Dari unsur-unsur tersebut, peneliti akan merepresentasikan peran ibu yang terdapat dalam film "Ibu Maafkan Aku" dengan menggunakan metode semiotik John Fiske.

\section{HASIL DAN PEMBAHASAN}

Pembahasan Peran Ibu Pada Level Realitas dan Level Representasi. Scene 1 Peran Ibu Setelah Bapak Meninggal Dunia.

Pada scene 1 ini level realitas yang menunjukkan representasi peran ibu adalah dari segi penampilan/gaya berpakaian: Hartini akan pergi bekerja mengenakan kaos panjang berwarna abu-abu, celana panjang dan ada kain yang diikatkan kembali di pinggangnya, rambut Hartini diikat satu menggunakan ikat rambut, membawa keranjang, membawa

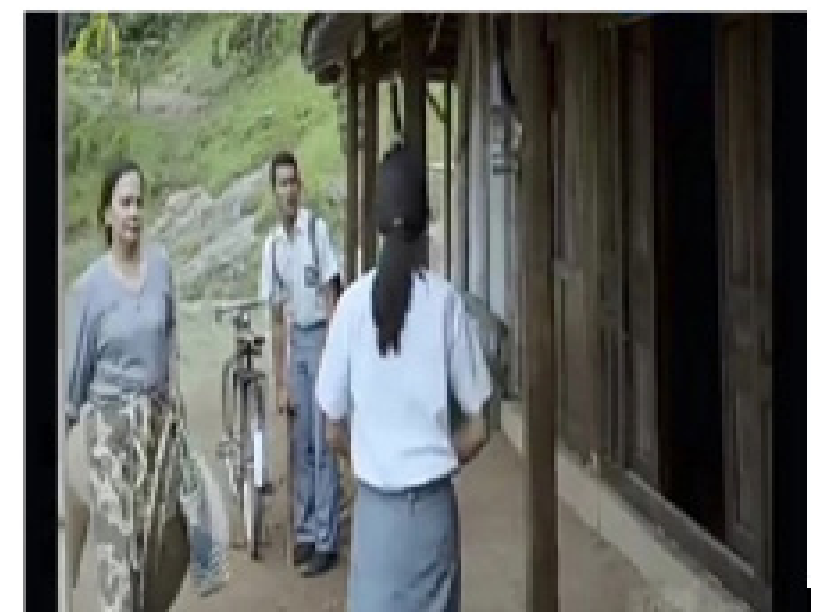

Sumber: Film Ibu Maafkan Aku, 2016

Gambar 2 detik 00:18:33

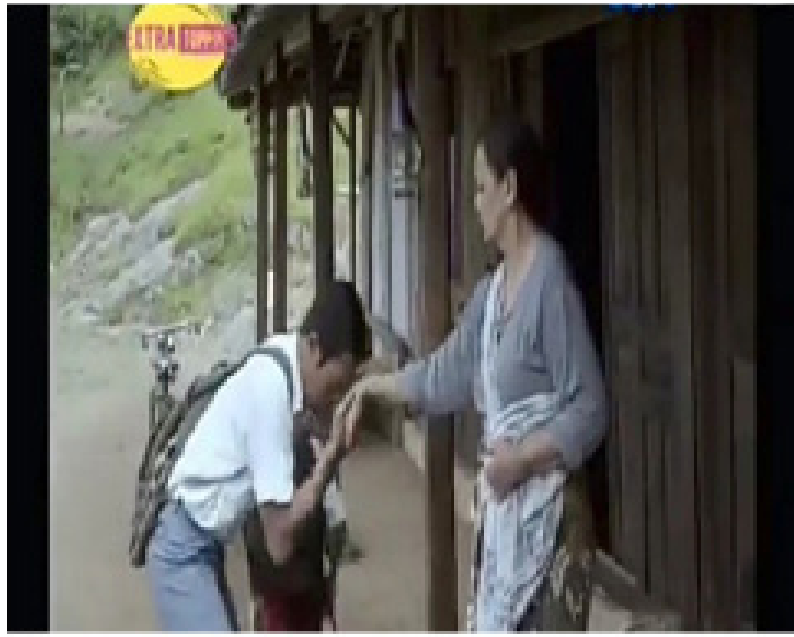

Sumber: Film Ibu Maafkan Aku, 2016

Gambar 3 detik 00:19:16

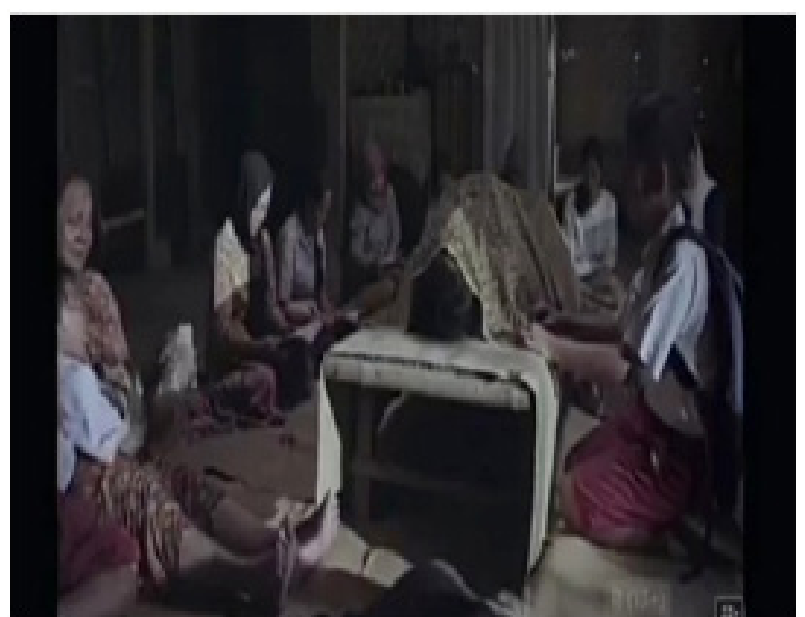

Sumber: Film Ibu Maafkan Aku, 2016

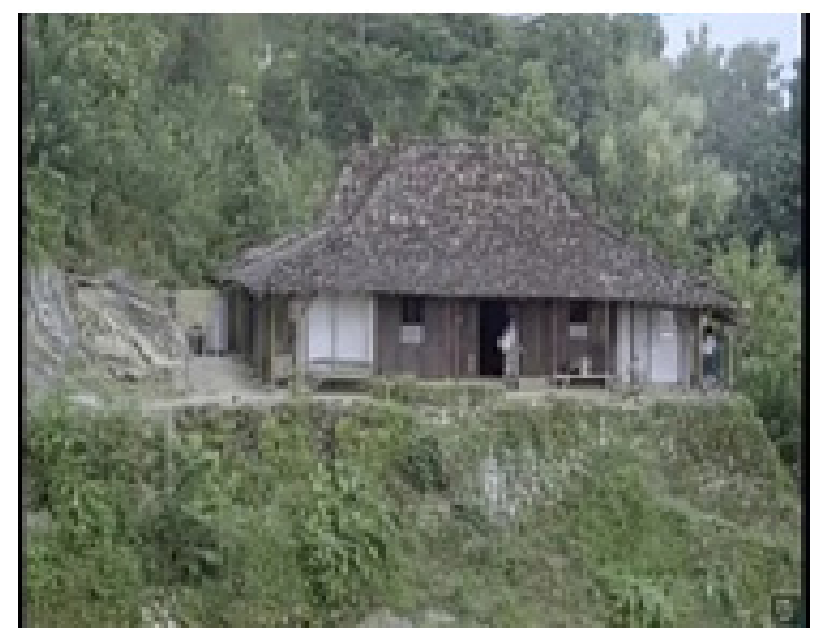

Sumber: Film Ibu Maafkan Aku, 2016

Gambar 4 detik 00:20:00 
caping/ tutup kepala dari anyaman bambu, alas kaki menggunakan sandal jepit. Pakaian Hartini termasuk ke dalam pakaian konservatif pakaian yang memegang teguh tradisi dan nilai keutamaan; cenderung menolak perubahan; bergaya tradisional atau kuno tetapi pakaian tersebut masih pantas dan enak dipandang mata (Thomson, 1999). Pakaian seperi Hartini memang sepantasnya dipakai untuk bekerja sebagai pemecah batu. Pakaian terkesan sederhana dan wanita biasa menunjukkan bahwa dirinya apa adanya. Warna abu-abu dari kaos panjang yang dikenakan Hartini mempunyai makna ketenangan dan keteduhan, kesederhanaan, kesedihan serta bertanggung jawab.

Representasi peran ibu dari segi riasan kulit wajah Hartini sawo matang. Hartini selalu tampil tanpa make-up atau natural. Riasan tersebutlah yang selalu Hartini pakai dikesehariannya. Riasan tersebut menunjukkan Hartini lebih mementingkan pekerjaannya atau aktifitas lainnya dibandingkan ia harus belama-lama menghabiskan waktunya di depan kaca. Mencermikan sosok wanita yang teguh dan pantang menyerah dalam hal apapun. Representasi peran ibu dari segi perilaku perhatian, mengayomi anak-anak, memberi nasihat dan menjadi penengah saat anakanaknya melakukan perdebatan kecil. Hartini menjadi ibu yang patut dicontoh atas peran gandanya dalam memberikan pengertian pada anak-anaknya. Memberikan pengertian kita harus melakukan segala aktifitas dengan gesit dan cekatan. Dari gestur dan ekspresi yang menunjukkan adanya peran ibu yaitu, Hartini yang sedang bersiap-siap bekerja karena Hartini bertanggung jawab sebagai tulang punggung keluarga untuk mencari nafkah. Dalam scene 1 ini Hartini nampak masih segar bugar jasmani dan rohaninya.

Dari ekspresinya Hartini sangat perhatian pada anak-anaknya, Hartini selalu mengajarkan anaknya agar sabar. Hal ini menunjukkan bahwa Hartini adalah sosok ibu yang baik serta ibu yang tanpa pamrih melakukan apapun demi anak-anaknya. Lingkungan masuk pada level realitas, dalam scene 1 berada di lingkungan yang masih asri, pohon-pohon masih rindang daunnya, jauh dari kebisingan kendaraan. Lingkungan rumah dan halaman rumah bersih tidak terlihat adanya sampah disekeliling nya. Di desa kebanyakan seperti ini, satu dengan rumah yang lainnya menjaga kebersihan rumah masing-masing.

Level representasi pada scene 1 yang menunjukkan adanya peran ibu dalam film "Ibu Maafkan Aku” dari segi teknik pengambilan gambar saat bapak meninggal menggunakan medium long shot diawal scene. Setelah dilakukan percakapan teknik pengambilan gambar pindah menggunakan long shot, pada 
saat Hartini bergegas dan menyegerakan pergi teknik pengambilan gambar menggunakan Bird Eye View. Shot gambar 1 saat diruang tamu rumah saat bapak meninggal menggunakan group shot dan establish shot, shot yang menampilkan keseluruhan pemandangan atau suatu tempat untuk memberikan orientasi tempat dimana peristiwa atau adegan itu terjadi. Pada gambar 2 menggunakan tree shot.

Pada gambar 3 menggunakan two shot. Gambar 4 menggunakan full shot. Adanya angle kamera pada gambar 1 high angle, posisi kamera harus menunduk untuk mengambil gambar. Gambar 2 dan 3 menggunakan normal angle dan low angle. Gambar 4 menggunakan high angle agar mempertunjukan keseluruhan set dan seluruh objeknya.. Dari segi pencahayaan pada scene 1 ini yaitu Front lighting / cahaya depan. Karakter dalam scene 1 ini untuk peran ibu yaitu tokoh protagonis. Dari segi musik dan suara, adanya musik dari alunan tabuhan gamelan-gamelan khas jawa dan ada suarasuara binatang yang khas pada pedesaan. Musik dan suara bertujuan untuk mempertegas adegan agar lebih menyentuh dan mendramatisir adegan.

Dialog yang menunjukkan representasi peran ibu dalam scene 1 ini sebagai berikut: Hartini : "Kenopo le?" melihat Banyu yang tergesa-gesa

Banyu : "Ban sepeda kempes bu" sambil mempompa ban sepedanya
Hartini

Banyu

Gendis

Banyu

Gendis

Banyu

Gendis

Banyu

Hartini

Banyu

Hartini

Banyu

Satrio

Hartini

Banyu

Gendis

Hartini

Gendis

Hartini
: "Bo ya di kompa" sambil mengambil topi/ caping yang dipakai dikepala.

: "Loh kamu belum siap-siap toh?"

: "Iki aku baru selesai cuci baju toh" sambil membawa ember cuciannya

: "Piye toh, aku ndak mau ketinggalan pelajaran matematika!! Cepet-cepet toh!" sambil mempompa ban sepeda

: "Iya se se........." berlari kedalam rumah, bergegas siap-siap berangkat ke sekolah

: "Cepet ndissssss.."

: "Iya tunggu"

: "Ndisss... kamu pergi sendiri saja. Aku telat!"

: "Bo ya adek nya ditunggu dulu toh mas...

: "Gendis lelet bu, biar jadi pelajaran buat dia!"

: "Tadi kan adiknya harus nyuci dulu..."

: "Loh aku juga, ambil kayu bakar,nimba aer tapi aku gesit bu" "Tri ayoooo"

: "Salimmmmmm......." sambil berteriak mengarah ke ibu dan mencium tangannya

: "Mas bo ya ditunggu....."

: "Wis bu, assalamualaikum" : "Aduh, piye toh mas Banyu terus aku gimana? Ibu kenapa ndak tahan mas banyu toh bu? Pada tega sama aku" sambil mengaruk kepalanya

: "Lain kali jangan lelet"

: "Assalamualaikum" berpamitan dan mencium tangan ibu

: "Waalaikumsalam"

Kalimat dialog diatas dapat kita identifikasi bahwa awal peran ibu dalam film tersebut yang memberi banyak pengertian dan sebagai 
penengah perdebatan kecil anak-anaknya. Meskipun tidak adanya sosok Bapak, Ibu selalu bisa beperan ganda ketika di dalam dan diluar rumah,Ibu bisa mengendalikan anaknya selalu mengkomunikan apapun secara bersamaan. Dan ibu mempunyai sikap yang selalu lembut.

\section{Scene 2 Peran Ibu Ikhlas Dalam Bekerja}

Pada scene 2 adanya level realitas dari gaya berpakaian. Hartini masih sama dengan scene 1 ia menggunakan kaos panjang berwarna abu-abu, celana panjang, kain berwarna putih tetapi sudah lusuh warnanya yang di simpan dibahu sebelah kanan. Rambut Hartini di ikat satu menggunkan tali rambut atau karet gelang. Pakaian Hartini termasuk kedalam pakaian konservatif pakaian yang memegang teguh tradisi dan nilai keutamaan; cenderung menolak perubahan; bergaya tradisional atau kuno tetapi pakaian tersebut masih pantas dan enak dipandang mata (Thomson, 1999). Sedangkan

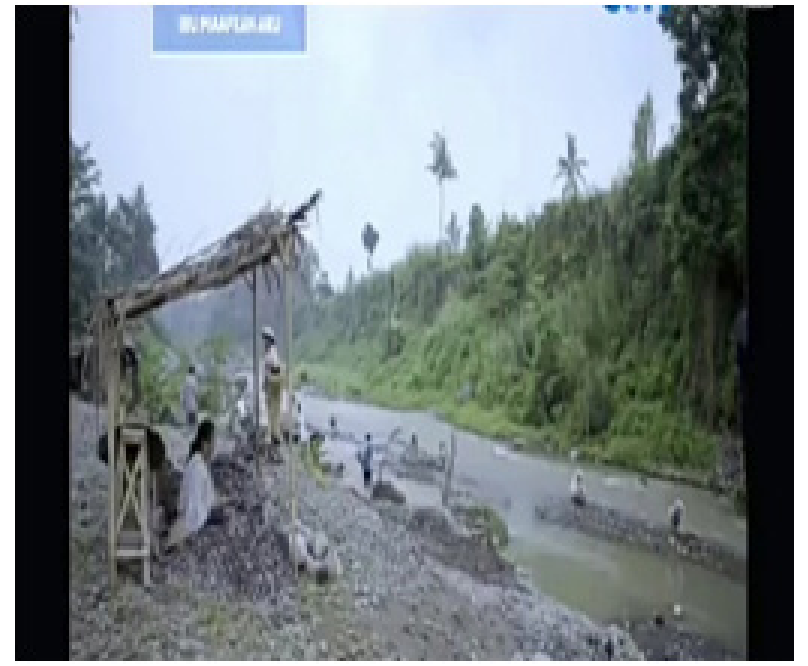

Sumber: Film Ibu Maafkan Aku, 2016

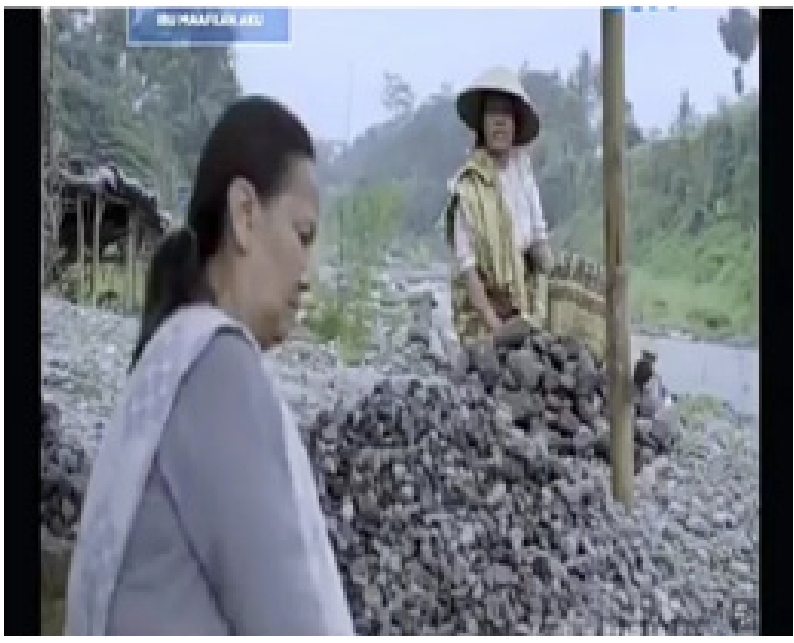

Sumber: Film Ibu Maafkan Aku, 2016

Gambar 6 detik 00:21:27

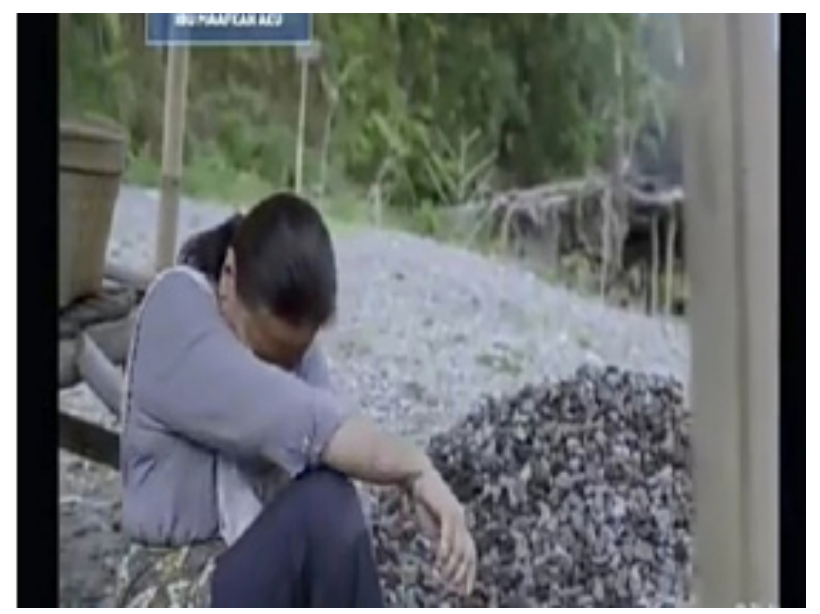

Sumber: Film Ibu Maafkan Aku, 2016

Gambar 7 detik 00:22:35

warna abu-abu dari kaos panjang Hartini mempunyai makna adanya ketenangan dan keteduhan, kesedihan dan bertanggung jawab.

Representasi peran ibu dari segi riasan kulit wajah masih sama dengan scene 1 Hartini berkulit sawo matang. Hartini selalu tampil tanpa make-up atau natural. Riasan tersebutlah yang selalu Hartini pakai dikesehariannya. Riasan tersebut menunjukkan Hartini yang apa adanya. Representasi peran ibu dari segi 
perilaku, meskipun Hartini nampak lelah dan sepertinya sempat memikirkan mengenai sekolah anaknya, namun ia selalu optimis dan percaya selalu ada jalan untuk mendapatkan rejeki. Perilaku ibu yang ikhlas meski bekerja berat sekalipun. Segi gestur dan ekspresi ibu peran ibu badannya sudah terlihat lemah di scene 2 ini. Apalagi setelah Hartini kesakitan karena ada serpihan pecahan batu yang ia pukul masuk kedalam matanya.Lingkungan pada scene 2 ini berada di sisi sungai yang biasanya Hartini memecah batu, sungai dan airnya masih deras, bersih dan masih sejuk dikelilingi banyak pohon-pohon yang rindang.

Level Representasi pada scene 2 menunjukkan adanya teknik pengambilan gambar 1 menggunakan Bird Eye View. Lalu gambar 2 saat bercakap-cakap dengan temannya menggunakan medium close up, selanjutnya gambar 3 scene wajah Hartini di close up. Sosok tubuh manusia mendominasi frame dan latar belakang tidak lagi menjadi dominan. Adegan percakapan normal biasanya menggunakan jarak medium close up. Shot pada gambar 1 menggunakan total shot dan establish shot.

Gambar 2 saat Hartini mengobrol dengan temannya menggunakan two shot. Gambar 3 menggunakan medium shot manusia biasa ditampakan dari atas pinggang sampai atas kepala dalam shot ini latar belakang dan objek utamapun nampak sebanding dan memperlihatkan sosok lebih jelas. Adanya angle kamera yaitu gambar 1 high angle dan low angle.

Gambar 2 dan 3 menggunakan normal angle posisi kamera sejajar dengan ketinggian mata objek yang diambil. Agar lebih dramatik adanya teknik lagi yg dipakai menggunakan Framing With Background, objek tetap fokus di depan namun latar belakang dimunculkan sehinggaada kesan indah. Dari segi pencahayaan pada scene 2 ini yaitu Front lighting / cahaya depan, cahaya merata dan tampak natural. Karakter dalam scene 2 ini untuk peran ibu tokoh protagonis yaitu tokoh utama yang mendukung cerita. Berikut adapun dari segi musik dan suara hanya terdengar suara air yang mengalir deras dan pukulan-pukulan batu yang sedang dipecahkan oleh Hartini. Musik dan suara bertujuan untuk mempertegas adegan agar lebih kuat maknanya. Adanya dialog yang menunjukkan representasi peran ibu yang bekerja dengan ikhlas dalam scene 2 ini sebagai berikut:

Teman Hartini: "Tin?" memanggil sambil menaruh bakul yang berisi batu Hartini : "Iyo..." sambil memecahkan batu dengan palu

Teman Hartini: "Aku dengar anak-anakmu itu pinter sekolah ne?"

Hartini : "Alhamdulilah, dapat beasiswa, bisa meringanke biaya"

Teman Hartini: "Iyo tin tin... seiki Banyu kelas telu sebentar lagi tamat dan kuliah terus kerja"

Hartini : : "Tapi Banyu ingin meruske sekolah pilot" sambil 
memecahkan batu dengan palu

Teman Hartini: “Apa jadi pilot?”

Hartini : "Iyo"

Teman Hartini: "Tin setau ku masuk sekolah pilot itu mahal. Kalo sd sampai sma itu murah, tapi masuk sekolah pilot biayane larang tenan tin, ndak cukup pake beasiswa. Wis moga-moga kamu kuat tin, menghidupi anakmu tin" sambil berdiri dan pergi ke arah sungai untuk mengambil kembali batu

Hartini : :Amiiinn" sambil menatap temannya pergi dengan tatapan yang kosong seakanakan seperti memikirkan pembicaraan tadi ada benarnya. Lalu dilanjutkan memecahkan batu kembali dan akhirnya pecahan batu mengenai mata Hartini dan meritih kesakitan pada matanya.

Kalimat dialog diatas merupakan identifikasi dari adanya peran ibu yang bekerja secara cuma- cuma. Dan adanya peran ibu dalam keluarga yang selalu bersemangat dan tidak kenal lelah, dan konsisten dalam mengurus keluarga. Ibu yang tidak panik dalam menjalankan hidup dan penuh rasa ikhlas dan selalu sabar. Dan dalam dialog ini Hartini tidak mengeluh akan adanya rasa sakit.

\section{Scene 3 Peran Ibu Memberikan}

\section{Pengertian Cinta Dan Pergaulan.}

Adanya level realitas pada scene 3 yang menujukkan representasi peran ibu adalah dari segi penampilan/ gaya berpakaian Hartini di scene ini memakai baju terusan yaitu daster bermotif batik berwarna coklat. Daster adalah model baju potongan longgar, biasanya panjang selutut dengan lengan pendek atau panjang, kebanyakan hampir dibuat dari bahan katun linean (Arti kata daster - Kamus Besar Bahasa Indonesia (KBBI) Online, 2019). Namun, ada juga yang dibuat dari bahan seperti sutera yang dipakai untuk tidur. Daster juga cocok untuk baju tidur karena bahan adem dan halus. Makna dari warna coklat tua yaitu memiliki kehangatan. Rambut Hartini masih di ikat satu dengan tali karet. Representasi peran ibu dari segi riasan kulit wajah Hartini berkulit sawo matang. Tanpa make up terkesan natural. Scene ini pun menunjukkan waktu malam yang bersiap akan tidur, dan Hartini apa adanya. Representasi peran ibu dari segi perilakunya, Hartini sebenarnya khawatir akan kisah cinta dan pergaulan Gendis. Tetapi, Hartini memberikan nasihat

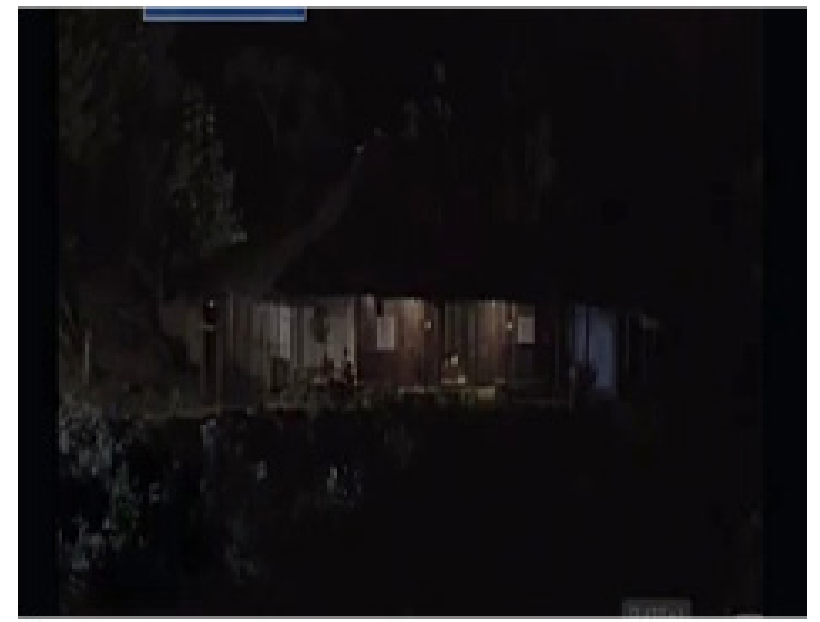

Sumber: Film Ibu Maafkan Aku, 2016

Gambar 8 detik 00:34:46 


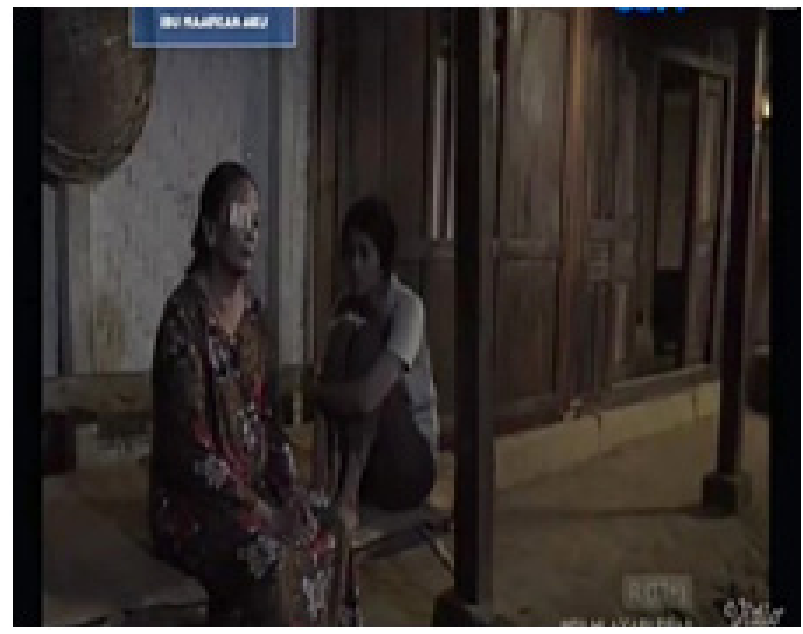

Sumber: Film Ibu Maafkan Aku, 2016

Gambar 9 detik 00:34:54

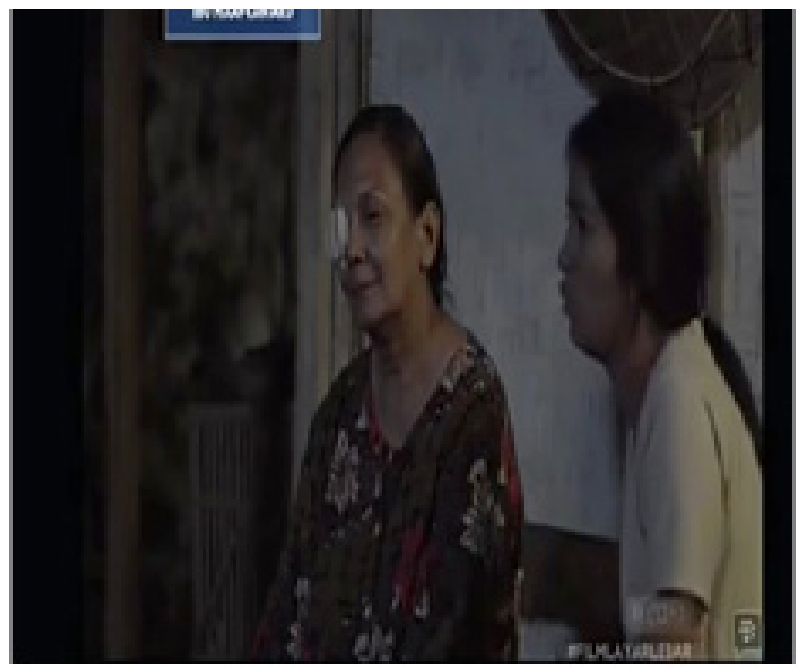

Sumber: Film Ibu Maafkan Aku, 2016

Gambar 10 detik 00:35:18

pada Gendis dan berbicara dengan lembut agar Gendis mengerti akan ke khawatiran Hartini. Dari segi gestur dan ekspresi peran ibu pada scene ini berbicara dengan volume suara yang kecil, dari wajah Hartini adanya ekspresi khawatiran akan Gendis yang ingin dibebaskan berhubungan dengan Panji. Hartini dan Gendis pun saling menenangkan satu sama lain dengan berpelukan. Serta memandangi wajah satu sama lain dan memandang suasana rumah di malam hari. Terlihat Hartini sosok ibu yang sangat penyayang. Adegan ini dilakukan dingkungan di depan rumah pada malam hari.

Level representasi peran ibu dalam scene 3 yaitu dari segi teknik pengambilan gambar 1 menggunakan bird eye view. Gambar 2 di mulai nya percakapan dengan Gendis menggunakan long shot tubuh fisik manusia telah tampakjelas namun latar belakang masih dominan dan long shot pembuka sebelum digunakan shotshotyang berjarak lebih dekat. Lalu gambar 3 menggunakan medium long shot teknik pengambilan gambar ini dipakai sampai dengan habis scene 3 ini.

Shot gambar 1 menggunakan total shot dan establish shot. Gambar 2 menggunakan medium shot. Fungsinya memperlihatkan sosok objek secara jelas serta two shot pengambilan gambar yang hanya menampilkan dua orang. Fungsinya memperlihatkan adegan dua orang yang sedang berkomunikasi. Pada gambar 3 medium long shot lebih dekat dari pada shot yang lainya.

Angle kamera gambar 1 high angle dan gambar 2 dan 3 menggunakan low angle. Dari segi pencahayaannya menggunakan Side lighting / cahaya samping. Tokoh Protagonis yaitu tokoh utama yang mendukung cerita. Dari segi musik dan suara yaitu terdengar adanya suara binatang-binatang malam seperti suara kodok, jangkrik,dan lain-lain. Dan musik dari 
alunan biola yang menambahkan akan kesan dramatik. Musik dan suara bertujuan untuk menambahkan dramatisir suasana film.

Adanya dialog dalam scene 3 ini yang menunjukkan peran ibu memberikan pengertian mengenai cinta dan pergaulan, sebagai berikut: Hartini : "Waktu ibu masih seumur kamu, bo langsung dilamar dan dinikahi bapak, ndak pake pacaran. Di jodohkan sama mbah tapi ternyata ibu dan bapak bisa bahagia, karna cinta itu datang kemudian" sambil duduk di depan dan memandang halaman rumah diiringi suara binatangbinatang kecil

Gendis : : "Ya zaman dulu masih ada jodoh-jodohan bu, sekarang udah ndak ada. Jodoh itu kan udah bukan ditangan si mbah atau orang tua" sambil mengubah arah duduknya ke depan dari yang tadinya menghadap pada ibu dan sekarang memandang halaman rumah

Hartini : "Bener, anak-anak sekarang ki lucu-lucu ndak mau dijodohkan mau nya berpacaran. Kebablasen terus kembung. Wajar toh ibu sama mas mu itu khawatir" sambil menganggukan kepala dan bibirnya tersenyum simpul kecil

Gendis : "Ibu ndak usah khawatir lah bu, ndis kan tau mana yang belum boleh mana yang boleh. Percaya sama ndis bu" sambil berbicara memandangi ibu

Hartini : "Ndo, sejak kamu dalam kandungan ibu, gusti Allah SWT sudah mengikat ibu sam dia anaknya dengan tali pusar walaupun tali itu harus diputus,tapi ikatan batin ibu sama anaknya tidak boleh
terputus.Jadi, yang terbaik buat kamu pasti yang terbaik buat ibu, dan yang terbaik buat ibu ne gusti Allah SWT memberikan jodoh yang terbaik buat kamu" sambil memegang tangan Gendis

Kalimat dialog di atas merupakan identifikasi ada nya peran ibu mampu memberikan dan memberi pehamhaman tentang sikap-sikap dan kebiasaan serta mengajarkan sabar atau tidak gegabah dalam mengambil keputusan, serta harus mengerti satu sama lain, karena seorang ibu tidak ingin anaknya masuk ke ruang lingkup salah, wajar saja bila adanya nasihat-nasihat yang harus kita patuhi.

\section{Scene 4 Peran Ibu Mendidik Anak}

\section{Dengan Dasar Agama}

Scene 4 adanya level realitas adanya peran ibu dari segi penampilan Hartini dalam scene ini memakai daster bermotif batik berwarna coklat muda atau krem. Daster adalah model baju potongan longgar, biasanya panjang selutut dengan lengan pendek atau panjang, kebanyakan hampir dibuat dari bahan katun linean (Arti kata daster - Kamus Besar Bahasa Indonesia (KBBI) Online, 2019). Daster pun nyaman dikenakan ketika beraktifitas dirumah, seperti Hartini daster dipakai agar lebih leluasa. Warna daster Hartini itu coklat muda yang mempunyai makna kejujuran, tanggung jawab dan kedewasaan. Rambut Hartini di ikat satu 
dan digulungkan seperti membentuk konde tetapi tidak rapih. Representasi peran ibu dari segi riasan kulit wajah Hartini berkulit sawo matang. Tanpa make up terkesan natural.

Scene ini pun menunjukkan Hartini sedang membersihkan halaman rumah. Jika ia dandan hanya untuk di rumah dan berkeringat rasanya tidak perlu. Hartini menunjukkan bahwa ia

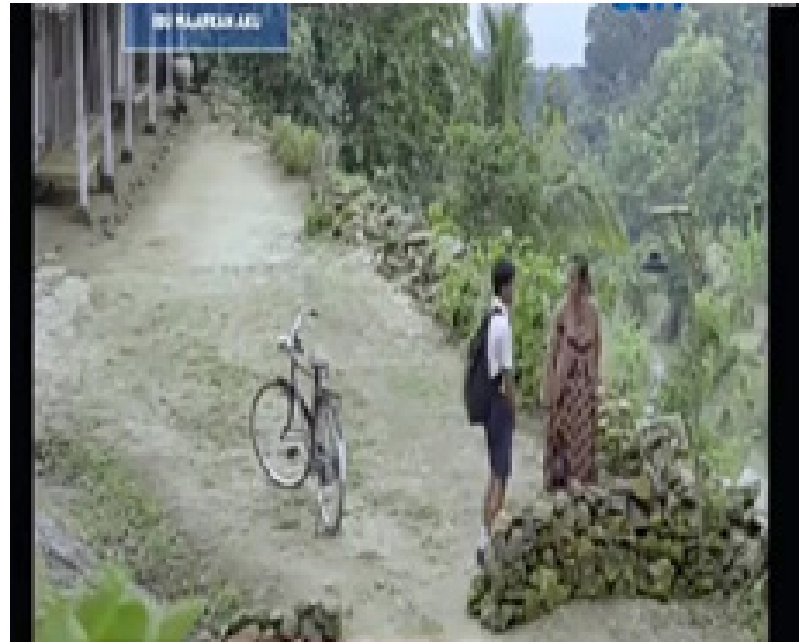

Sumber: Film Ibu Maafkan Aku, 2016

Gambar 11 detik 01:40:09

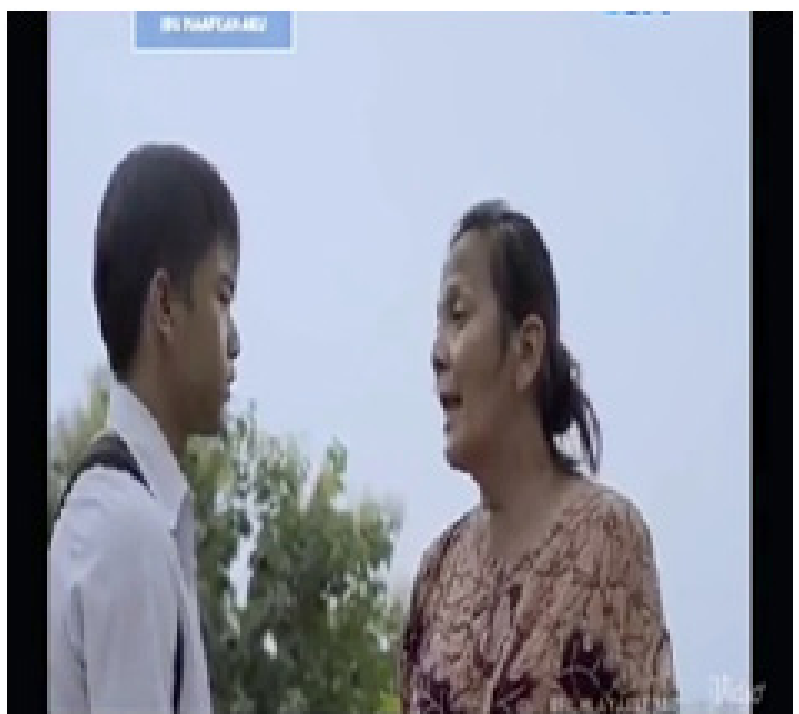

Sumber: Film Ibu Maafkan Aku, 2016

Gambar 12 01:39:47

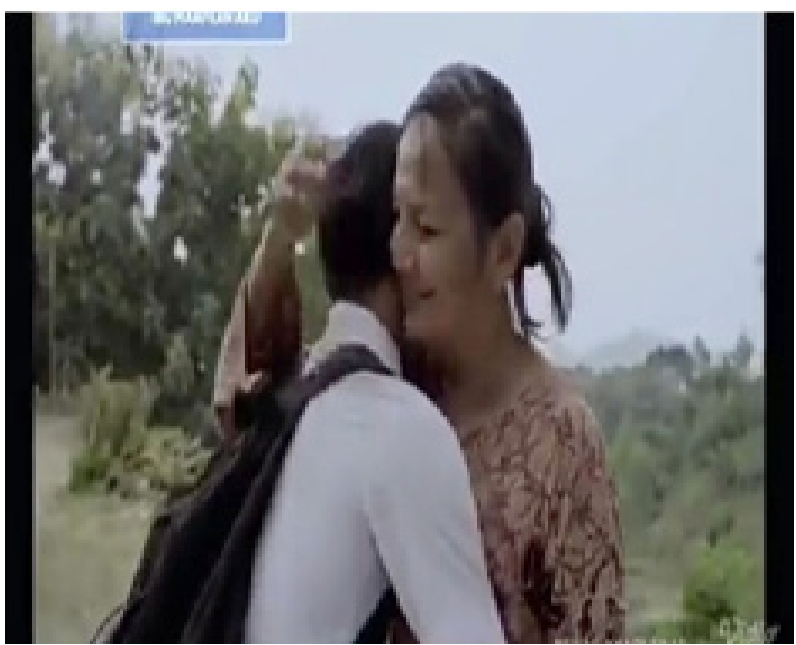

Sumber: Film Ibu Maafkan Aku, 2016

Gambar 13 01:40:58

adalah wanita apa adanya. Representasi peran ibu dari segi perilakunya, Hartini memeluk Satrio memberikan ketenangan dengan peluk. Mencium kening agar merasa ia masih dihargai. Dan mengusap-usap kepala Satrio agar ia terdorong untuk lebih semangat lagi dalam belajar. Dari segi gestur dan ekspresi peran ibu pada scene ini berbicara dengan Satrio lembut dan sabar. Hartini memberikan ekspresi santai atau biasa saja mengetahui Satrio tidak naik kelas. Dengan Hartini bersikap dan memberi respon seperti ini tidak membuat Satrio ketakutan, melainkan menjadikan Satrio anak yang lebih terbuka lagi. Lingkungan masih di sekitar halaman rumah yang dikeliingi pohon yang rindang dan halaman rumah yang bersih.

Level representasi peran ibu dalam scene 4 yaitu dari segi teknik pengambilan gambar 1 percakapan dengan Bird Eye View lalu gambar 2 long shot. Gambar 3 Satrio mendekat dan 
memeluk Hartini menggunakan medium shot.

Dan seperti itu sampai scene ini selesai. Shot yang digunakan pada gambar 1 menggunakan full shot pengambilan gambar penuh objek dari kepala hingga kaki. Fungsinya memperlihatkan objek beserta lingkungannya. Pada gambar 2 dan 3 two shot. Kamera angle menggunakan high angle sudut pengambilan gambar tepat diatas objek, pengambilan gambar seperti ini memiliki arti yang dramatik. Dari segi pencahayaan menggunakan front lighting / cahaya depan. Karakter Hartini lemah lembut dan tokoh protagonis yaitu tokoh utama yang mendukung cerita. Dari segi musik dan suara nya itu adanya suara yang natural adanya binatang-binatang kecil di pedesaan. Musik dan suara bertujuan untuk memperkuat makna.

Adanya dialog dalam scene 4 ini yang menunjukkan peran ibu mendidik anak dengan dasar agama, sebagai berikut:

Hartini : "Loh kenapa le?" sedang membereskan batu dihalaman rumah, lalu menoleh kekanan menyadari adanya Satrio yang sedang memandangnya

Satrio : "Maafin tri yo buuuu" tanganya dikepal, dan berlari ke arah ibu dan langsung memeluknya

Hartini : :Kenapa?" kaget

Satrio : "Aku ndak naik kelas bu" sambil memeluk ibu

Hartini : "Alaaaah, ndak naik kelas toh. Ibu pikir ada apa" sambil mengelus rambut Satrio dan bersikap santai

Satrio : "Loh ibu ndak marah?"
"Aku malu bu, di keluarganya kita cuman aku yang ndak pinter. Masa adiknya dokter dan pilot ndak naik kelas"

Hartini : "Ndak naik kelas itu ndak bikin langit jadi runtuh toh?" sambil kembali mengelus rambut Satrio

Satrio : "Iyo bu"

Hartini : "Tiap orang itu punya kelebihannya sendiri-sendiri. Mungkin kamu ya jadi pinternya dengan ngulang. Mas mu punya kelebihannya sendiri, mbak mu juga punya kelebihan sendiri. Kamu ya kamu Satrio. Yang penting buat ibu solat lima waktunya ndak ditinggal dan tetep sayang sama ibu" sambil menepuk bahu Satrio

Satrio

: "Iyo bu, walaupun Tri ndak pinter tapi Tri yakin masih bisa nyenengin ibu" Satrio memeluk ibu

Hartini : Amiiin, insya allah" memeluk Satrio

Kalimat dialog di atas merupakan identifikasi ada nya peran ibu dalam mendidik anak dengan dasar agama. Ibu sangat berpengaruh dalam pendidikan beragama dan menyalurkan perkembangan anak. Peran ibu dalam dialog ini pun mendukung dan menemani tumbuh kembang anak. Karena adanya kelembutan hati ibu dan diberikannya ketenangan agar mencoba untuk menerima kenyataan sekalipun pahit dan diterima dengan lapang dada. Dan Hartini menghibur hati Satrio dengan cara yang bijaksana tidak membuat hati sang anak kecewa.

Pembahasan Peran Ibu Pada Level 
Ideologi: Ada dalam teori the code of television John Fiske, level yang ketiga adalah ideologi. pada level ini mencakup adanya kode-kode representasi dihubungkan dan diorganisasikan kedalam kepercayaan yang ada dimasyarakat atau representasi atas suatu realita. Peneliti membedah adanya peran ibu dalam film "Ibu Maafkan aku" dengan adanya ideologi yang terdapat dalam film ini yaitu ideologi ibuisme. Istilah ibuisme adalah sosok perempuan yang mampu memberikan atau melayani suami, anak, masyarakat serta negaranya, perempuan diharuskan memberikan tenaga kerjanya secara cuma-cuma tanpa mengharapkan prestise atau kekuasaan apapun. Konstruksi seorang ibu dengan demikian dicitrakan secara biologis oleh masyarakat sebagai perempuan yang sudah menikah dan sudah memiliki anak. Citra psikologis seorang ibu dalam konsep ibuisme sengaja diciptakan dan dipelihara. Ini ditunjukan dengan adanya peran nenek sebagai salah satu agen ibuisme, yang bertugas mendidik dan mengajari anaknya untuk memiliki keterampilan-keterampilan seperti layaknya gambaram seorang ibu yang diidamkan (Suryakusuma, 2011).

Julia Suryakusuma merupakan aktivis perempuan intelektual Indonesia yang berani menganalisis secara serius hubungan gender masyarakat, meskipun ia sempat mendapatkan intimidasi. Pada tingkat tertentu, ibuisme merupakan bentuk eksplisit versi Indonesia dari doktrin yang mengingkari kekuatan sosial perempuan dengan menetap wilayah mereka dirumah semata.

Pada film "Ibu Maafkan $A k u$ " paham mengenai ibuisme sangat tergambarkan.. Peran ibu dalam film ini pun mengabdi pada suami, walaupun suaminya sudah tiada. Hartini yang menjadi sosok ibu dalam film memiliki peran ganda sebagai orang tua. Di film ini level ideologi ibuisme sudah terepresentasikan oleh Hartini.

Diceritakan dalam film, bagaimana Hartini sebagai wanita yang memiliki anak, dan harus menghidupi mereka seorang diri serta mempunyai tanggungjawab yang besar untuk mendidik. Hartini bekerja sebagai pemecah batu. Tidak pernah menyerah dan mengeluh atas apa yang selalu Hartini rasakan. Hartini bekerja dengan ikhlas untuk anak-anak. Terlihat, bagaimana ibuisme yang dimiliki oleh Hartini di dalam film hanya karena tanggungjawab, tuntutan lingkungan sosial.

\section{SIMPULAN}

Simpulan dari penelitian berdasarkan pembahasan yang telah dijelaskan mengenai bagaimana representasi peran ibu dalam film "Ibu Maafkan Aku” dapat disimpulkan bahwa representasi peran ibu yang ditemukan oleh peneliti dalam film tersebut adalah sebagai 
berikut, yaitu: Representasi peran ibu yang ditemukan oleh peneliti dalam film tersebut adalah sebagai berikut, yaitu: Level realitas mengetahui adanya tanda-tanda yang terjadi di penampakan luar atau fisik dari tokoh yang di analisa seperti pada tokoh ibu yang memperlihatkan penampilan, lingkungan, perilaku dan sebagainya. Level representasi adanya teknik kode untuk lebih spesifik pada objek yang di fokuskan seperti adanya kamera, pencahayaan, penyutingan, musik, suara, dan lainnya. Level Ideologi adanya suatu pemikiran atau pendapat tentang peran ibu yang ada dalam film dan di beri kesimpulan adanya penyebutan istilah ibuisme dalam film Ibu Maafkan Aku. Dengan di jelaskan secara rinci semoga dapat dimengerti untuk menjadikan skripsi ini sebagai acuan penelitian selanjutnya, dan bisa lebih baik dari pada skripsi yang terdahulu.

\section{DAFTAR PUSTAKA}

Abbas, A. S. (2009). Mukjizat doa dan air mata ibu. Jakarta: QultumMedia.

Abidin, Y., Mulyati, T., \& Yunansah, H. (2017). Pembelajaran literasi strategi meningkatkan kemampuan literasi matematika, sains, membaca, dan menulis. Jakarta: Bumi Aksara.

Ardianto, E., Komala, L., \& Karlinah, S. (2007). Komunikasi Massa: Suatu Pengantar. Bandung: Simbiosa Rekatama Media.

Arti kata daster - Kamus Besar Bahasa Indonesia (KBBI) Online. (2019). KBBI
Online. https://kbbi.web.id/daster

Batara, B. (2016). Review: Ibu maafkan aku (2016) | IDFC. Indonesian Film Critics. http://idfilmcritics.com/indonesian-movie/ ibu-maafkan-aku-2016-review/

Budiman, K., \& Ajidarma, S. G. (2004). Semiotika visual. Yogyakarta: Buku Baik.

Fiske, J. (2014). Pengantar ilmu komunikasi edisi ketiga. Jakarta: RajaGrafindo Persada.

Gunarsa, S. D. (2001). Pikologi psikis: Anak, remaja dan keluarga. Jakarta: Gunung Mulia.

Ibu Maafkan Aku(2016).(2016). FIlm Indonesia. http://filmindonesia.or.id/movie/title/ lf-i013-16-777924_ibu-maafkan-aku\#. $\mathrm{XkpCgyMxVdh}$

Lirsa, A. (2008). Ibu professional. Solo: Samudera.

Moleong, L. J. (2011). Metodologi penelitian kualitatif. Bandung: Remaja Rosdakarya.

Permana, R. S. M., Puspitasari, L., \& Indriani, S. S. (2019). Strategi promosi pada tahapan pra-produksi film "Haji Asrama" (HAS). ProTVF: Jurnal Kajian Televisi Dan Film, 2(2), 145-156. https://doi.org/10.24198/ ptvf.v2i2.20818

Rusadi, U. (2015). Kajian media: Isu ideologis dalam perspektif, teori dan metode. Jakarta: Rajawali Press.

Sugiyono. (2012). Metode penelitian kuantitatif, kualitatif, dan kombinasi. Bandung: Alfabeta.

Suryakusuma, J. (2011). Ibuisme negara: Konstruksi sosial keperempuanan orde baru. Depok: Komunitas Bambu.

Sutorini, M. P., Alif, M., \& Sarwani, S. (2019). Semiotika gender dalam film Brave. ProTVF, 3(1), 101-112. https://doi. org/10.24198/ptvf.v3i1.21246

Thomson, C. (1999). Pengertian konservatif - pengertian menurut para ahli. 
pengertian menurut para ahli (arti kata \& Vera, N. (2014). Semiotika dalam riset

definisi menurut para ahli). https://www. pengertianmenurutparaahli.net/pengertiankonservatif/ komunikasi. Bogor: Ghalia Indonesia.

Vivian, J. (2015). Teori komunikasi massa (8th ed.). Jakarta: Kencana. 